\title{
Application of Flipped Class Model in Promoting Reform of Physical Education Curriculum
}

\author{
Wenchao Li \\ Capital University of Physical Education and Sports, Beijing, 100191
}

Keywords: physical education (PE) teaching; reform; flipped class model of PE

\begin{abstract}
Since 2011, flipped class model has always had an important influence on the educational circles. It greatly changes the traditional teaching procedures, facilitates understanding the learning situation of each student in accordance with the relevant theoretical knowledge and the content of the theory of zone of proximal development, and encourages autonomous, independent and efficient learning by students, where teachers properly guide students according to their aptitude, and establish a new relationship between teachers and students. Compared with the traditional classroom teaching in the past, flipped class model mainly improves the efficiency of classroom teaching by applying computer and network technology therein, and is a teaching method with a broad development space. As found by investigation, the physical health of teenagers in China presents a downward trend, and the current PE curriculum reform of China aims at participation in exercises, sport skills, physical health, mental health and social adaptation. In order to better achieve the objectives, this paper analyzes the theory and time value of flipped class model applied to physical education teaching based on teaching experiences.
\end{abstract}

\section{Background of PE curriculum reform}

In 2001, China implemented the 8th new PE curriculum reform, which put forward 5 major new objectives of PE curriculum teaching, specifically including participation in exercises, sport skills, physical health, mental health and social adaptation, and put forward the cultivation direction and objectives in many aspects, such as physical health, mental health, knowledge and skills, will and emotional attitude, for students at various stages of basic education. Different from the previously used Outline, the new curriculum reform proposes the teaching objectives of invigorating health and improving athletic ability, sets 5 major teaching objectives of PE curriculum: participation in exercises, sport skills, physical health, mental health and social adaptation, and fully reflects the cultivation direction of quality teaching. However, China has implemented the PE curriculum teaching standard proposed in 2001 for a long term. PE teachers and relevant PE experts are also constantly making explorations and researches, and hope to find a comprehensive teaching objective combining the 5 major objectives, where some good achievements have been made, but there are still a lot of lessons from failure. The emergence of flipped class model has changed the disadvantages of current teaching to a certain extent, and has improved the rationality and scientific nature of the PE curriculum.

\section{Specific connotation and characteristics of flipped class model}

Flipped class model is translated from English "Flipped Class Model", and is called by some experts as the flipped class or inverted class teaching model. The traditional teaching mode means that teachers give lessons and arrange after-class homework, while students use their spare time to complete review, check unmastered knowledge, and make up for deficiencies. However, for flipped class model, students shall study in their spare time according to the videos provided by teachers, raise questions when having class on the second day, and solve the questions through joint discussion between classmates and teachers. The remaining time in class is mainly used to solve students' confusions, show questions, and ask students to discuss and exchange about the questions. Flipped class model was originated in two chemistry teachers of the United States, because some of 
the students were very far away from school with complex family affairs, and often missed regular class time, so that the teachers uploaded teaching videos on the Internet for their learning, and achieved good effects, which then attracted attentions of many educators. Later, through continuous perfection and improvement by many experts in different countries, it becomes a very popular teaching mode.

Change of the teaching process can greatly affect the teaching effects. With flipped class model, students can learn by watching videos at home, complete study according to their own situation, and then test the learning situation through a learning exam in a system designed by teachers. Based on the principle of "passing the exam by full marks (10)", students begin inverted test after completing part of study, will exit evaluation if failing to give all answers correctly, relearn knowledge points mistakes of which occur, and have a test again, until they can give all answers correctly. Therefore, compared to the previous teaching process of starting guiding individuals after explaining collective knowledge, flipped class model creates a better independent learning environment for students, and reduces the pressure of students, so that students complete knowledge learning according to their own ability, can rationally control their own learning pace, and firmly grasp the basic knowledge. Practices have proven that this learning style can mobilize students' learning enthusiasm very well, so that they take the initiative to participate in study. Therefore, students can greatly improve the classroom efficiency and form solid basic knowledge by completing deep knowledge learning after class.

Teaching links, such as raising questions and discussing questions by students, will also be designed in traditional classroom teaching, but these questions are all associated with the contents to be explained by teachers, and cannot effectively solve the problems in student learning. Flipped class model changes from simply explaining knowledge in class to the process of knowledge internalization among students, so that students can indicate their confusions, and then get proper guidance from teachers, or can also get answers by discussing with their classmates. Through evaluation of students' situation, teachers reasonably arrange learning contents in the next stage, and realize the model of teaching at different levels. In such classroom teaching, students complete knowledge internalization by communicating and exchanging with teachers, and classroom teaching becomes a dynamic development process.

Educationalists have always advocated that teaching should be centered on students and students should be taught in accordance with their aptitude. Traditional teaching cannot put it into practice very well. Flipped class model can achieve this objective to a certain extent. Students can control their own learning location, time, schedule and other factors, and conduct self-test to determine their learning situation. In fact, teachers take heavier responsibility. Teachers become guiders and facilitators for student learning, and mainly answer students' questions. Higher requirements are put forward for teachers. Teachers need to scientifically and effectively design teaching videos, understand students' learning situation at each stage, do a good job in guiding students, and teach students in accordance with their aptitude, so that students can individualize their learning.

\section{Application and analysis of flipped class model in PE teaching}

At present, students' physique is gradually declining, and students are faced with severe learning pressure. PE teaching shoulders important tasks of improving students' physical quality, and shall not only teach students basic sport skills, but also cultivate students' love of sports exercises. Flipped class model plays an important role in cultivating students' sport skills and exercise interests, and promotes good realization of the objective of new PE curriculum reform. The application of flipped class model in PE education is introduced below.

When students are learning sport skills, teachers should first demonstrate for actions by traditional teaching method, will explain complex skills using relevant mentoring images in a relatively long time. However, the PE classroom teaching time is limited, and students don't have enough exercise time. Therefore, it is very difficult to correctly grasp several sport skills, and sometimes it is difficult to learn only one of the sport skills. Therefore, if the flipped class model is used for PE teaching, students can master various sport skills by watching and replaying video after 
class, so that they can clearly learn the details of each action. Students learn in a relaxed atmosphere, can get better effects, quickly grasp key actions, and then exercise and consolidate the actions using the PE class time. In this way, every student can better learn every sport skill.

Traditional PE teaching means collective teaching of students in the whole class by a teacher based on the arrangement of teaching contents, where some students may neither be able to keep up with the pace, nor master the sport skills very well, while some students can learn the sport skills easily. Thus, it is not conducive to cultivation of interests in exercises for the two parts of students, all of whom will lose interests in sports exercises and PE curriculum after a long time. For flip classroom model, PE teachers can consider the characteristics of students and sports items, arrange different expansion links, arrange action learning of higher difficulty for students who can easily learn objective tasks of the curriculum, and improve such students' interests in PE curriculum.

All PE teachers have their own professional items, and due to gradual increase in their ages, they may not better demonstrate for some sports items. With flipped class model, teachers can arrange students to learn some exercises at which the teachers are not good by watching videos of some other teachers, so as to stimulate students' love of PE curriculum.

Flipped class model means that students can independently study based on videos before class, discuss and exchange about problems in class time, can consult teachers, and can also ask students to make explorations and discovery, so as to promote communication between students and teachers very well, and realize the teaching objectives of psychological health and social adaptation.

\section{Conclusion}

Flipped class model can increase the time for students to exercise sport skills, reasonably arrange all kinds of teaching equipment, well combine theory with practice, improve students' learning interests in PE curriculum, ensure that every student can master various exercise functions, and finally achieve the objectives and tasks of PE curriculum reform.

Flipped class model can allow students to select sports items according to their own interests, hobbies and ability, and achieve teaching according to students' aptitude, so as to help students to form good sport skills, ensure their physical health, insist on sports exercises for a long time, and cultivate good life and learning habits.

\section{Acknowledgment}

National Social Science Fund Educational Education Youth Project + "up-and-down", the first line of urban high school sports development and countermeasures research + CLA 130196

\section{References}

[1] Luo Min. On the Reasons for Flipped Class Model and Mini-Course Suitable for Application in PE Teaching of Secondary Vocational Education [J]. Exam Weekly, 2015 (30): 96-96.

[2] Zhu Guozheng. Application of Flipped Class Model in PE Teaching [J]. Sports Goods \& Technology, 2016 (12): 99-100. 